\title{
Early-Life Malaria Exposure and Adult Outcomes: Evidence from Malaria Eradication in India
}

\section{Citation}

Cutler, David, Winnie Fung, Michael Kremer, Monica Singhal, and Tom Vogl. 2010. Early-life malaria exposure and adult outcomes: evidence from malaria eradication in India. American Economic Journal: Applied Economics 2(2): 72-94.

\section{Published Version}

doi:10.1257/app.2.2.72

\section{Permanent link}

http://nrs.harvard.edu/urn-3:HUL.InstRepos:5344529

\section{Terms of Use}

This article was downloaded from Harvard University's DASH repository, and is made available under the terms and conditions applicable to Open Access Policy Articles, as set forth at http:// nrs.harvard.edu/urn-3:HUL.InstRepos:dash.current.terms-of-use\#OAP

\section{Share Your Story}

The Harvard community has made this article openly available.

Please share how this access benefits you. Submit a story.

\section{Accessibility}




\title{
Early-life Malaria Exposure and Adult Outcomes: Evidence from Malaria Eradication in India
}

\author{
David Cutler ${ }^{1}$ Winnie Fung ${ }^{2}$ Michael Kremer ${ }^{3}$ Monica Singhal ${ }^{4}$ Tom Vogl $^{5}$
}

November 2009

\begin{abstract}
We examine the effects of exposure to malaria in early childhood on educational attainment and economic status in adulthood by exploiting geographic variation in malaria prevalence in India prior to a nationwide eradication program in the 1950s. We find that the program led to modest increases in household per capita consumption for prime age men, and the effects for men are larger than those for women in most specifications. We find no evidence of increased educational attainment for men, and mixed evidence for women.
\end{abstract}

JEL Codes: H51, I18, J24

Keywords: malaria, health, and education

\footnotetext{
${ }^{1}$ Harvard University and NBER. Email: dcutler@fas.harvard.edu

${ }^{2}$ Harvard University. Email: fung@fas.harvard.edu

${ }^{3}$ Harvard University and NBER. Email: mkremer@fas.harvard.edu

${ }^{4}$ Harvard University and NBER. Email: monica_singhal@harvard.edu

${ }^{5}$ Harvard University. Email: tvogl@fas.harvard.edu
}

We are grateful to the National Malaria Eradication Programme of India for its generous assistance, to Petia Topalova for help with the National Sample Survey, to Scott Walker for help with GIS, and to Lakshmi Iyer for making available her data on agriculture in Indian districts. We also thank participants of the Center for International Development Conference on Health Improvements for Economic Growth, the Harvard Initiative on Global Health seminar series, three anonymous reviewers, and the Editor Esther Duflo for their comments. Vogl thanks the NSF for support. 


\section{Introduction}

Malaria, a disease that has afflicted humans for more than 10,000 years (Dunn, 2003), today infects some 300 million people each year, killing one million (WHO 2001). Despite important advances in its control during the twentieth century, the disease remains stubbornly prevalent throughout much of the world. Faced with this huge global burden, international organizations have redoubled their efforts to combat the disease.

Many argue that improving health, while important in itself, can also lead to higher economic growth and development. Gallup and Sachs (2001) argue that falciparum malaria endemicity is negatively correlated with economic growth across countries. ${ }^{1}$ In contrast, Acemoglu and Johnson (2007) argue that the wave of international health innovations that began in the 1940s did not lead to a disproportionate increase in log per capita GDP in the areas with high pre-intervention disease burden.

In this paper, we extend this literature by studying the effects of childhood exposure to malaria eradication on human capital accumulation and economic status in adulthood. Malaria has been hypothesized to have lifelong effects on skill acquisition through at least three channels: its effects on cognitive ability, school absenteeism, and fetal development (e.g., Sachs and Malaney, 2002). ${ }^{2}$ These sequelae do not necessarily imply that eradication of the disease will always lead to improvements in schooling attainment. As emphasized by Bleakley (2009), in a country with widespread child labor, the effect of improved childhood health on the labor-schooling decision is ambiguous because malaria could affect children's productivity in both education and work. ${ }^{3}$ In this case, eradication could boost adult income even without affecting schooling attainment. The health benefits of malaria reduction could result in improved physical and mental condition later in life and therefore higher labor market productivity. Furthermore, a reduction in school absences could enhance learning, thus improving literacy and earnings even holding years of schooling constant. ${ }^{4}$

\footnotetext{
${ }^{1}$ Other macroeconomic studies, such as those by Bloom and Canning (2005) and Alleyne and Cohen (2002), also conclude that improvements in health can lead to higher economic growth.

${ }^{2}$ Randomized evaluations have documented effects of malaria on cognitive ability and school absenteeism (Leighton and Foster, 1993; Aikins, 1995; Brooker, et al. 2000; Clarke, et al. 2008). Additionally, Jukes et al. (2006) find suggestive evidence of a positive long-run effect of childhood malaria prophylaxis on educational attainment.

${ }^{3}$ Similarly, the cognitive gains from eradication can lead to increased or decreased schooling investment depending on the balance of income and substitution effects. The conventional wisdom is that cognitive ability is complementary to schooling (Card, 2001), but this is an empirical claim, not a theoretical prediction.

${ }^{4}$ Eradication may also lead to the survival of children with poorer health and weaker cognitive skills. This is unlikely to be the case in our setting because, as described below, the most prevalent form of malaria in India is generally non-fatal.
} 
We use the national malaria eradication program in India in the 1950s as a quasi-experiment and exploit geographic variation in malaria prevalence prior to the eradication campaign. We compare gains for cohorts born before and after the program in areas with varying pre-eradication prevalence. These differences-in-differences estimates show no gains in literacy or primary school completion for areas that experienced large reductions in malaria to those that experienced small reductions. ${ }^{5}$ We do, however, observe modest relative increases in economic status (proxied by household per capita household expenditure) for prime age men. This effect is robust to using quite localized sources of geographic variation and to instrumenting for pre-eradication prevalence using geographic and climate factors, although in our most demanding specification (identified using within-region variation and including district linear trends), the point estimates remain similar but become imprecise. We do not observe significant increases in expenditure as a result of the program for women, and these gender differences cannot be explained by differences in household composition of treated men and treated women. In most, but not all, of our specifications, the gender differences are statistically significant. This suggests that improved labor market productivity may underlie the observed effects for men, given their much higher rates of labor force participation.

Our findings relate most closely to two recent papers that examine the effects of malaria eradication campaigns in other parts of the world. Bleakley (2009) studies the effect of malaria eradication campaigns on the income and education of men in the United States, Brazil, Colombia, and Mexico, finding that childhood exposure to malaria lowers labor productivity and leads to lower adult income. Results for years of schooling are mixed. Lucas (2009) uses a similar strategy to study ever-married women in Paraguay and Sri Lanka, finding that malaria eradication increases female education and literacy rates. ${ }^{6}$ We discuss our findings relative to this literature in Section 5. Together with these papers, our results suggest that tropical disease control generates important economic benefits, but that it is unlikely to be a major driver of economic growth.

The paper proceeds as follows. Section 2 describes malaria in India in the pre-eradication era

\footnotetext{
${ }^{5}$ These results differ from an earlier working paper draft. This version corrects errors discovered in the original program files and extends the empirical analysis along a number of dimensions. The IV results do suggest improvements in educational attainment resulting from the program for women; we discuss these results in detail below.

${ }^{6}$ Two other studies use weather conditions to instrument for malaria exposure in the United States and examine the effects on long run health and economic outcomes. Hong (2007) finds that malarial risk leads to adverse long run health outcomes, lower labor force participation, and lower wealth. Barecca (2009) finds that in utero and postnatal malaria exposure leads to lower educational attainment. Lucas (2007) finds that malaria eradication in Sri Lanka led to an initial increase in fertility followed by lowered fertility in the second generation.
} 
and discusses the National Malaria Control Program in India and its effectiveness. Section 3 outlines our empirical strategy. Section 4 describes the data. Section 5 presents our results, and Section 6 concludes.

\section{Malaria in India}

Efforts to control malaria in India date back to the early 1900s but were revolutionized in the mid-1940s with the advent of DDT (dichlorodiphenyl trichloroethylene). ${ }^{7}$ DDT was effective, nontoxic to humans, and “dirt-cheap to manufacture” (Desowitz, 1991). Aggressive campaigns using DDT were launched almost simultaneously around the world, leading to the rapid eradication of malaria in Taiwan, much of the Caribbean, the Balkans, parts of northern Africa, northern Australia, and large parts of the South Pacific (Davis, 1956).

DDT was first used in India by the military in 1944 and became available for civilian antimalaria operations in 1945. Successful pilot programs in the late 1940s led the national Planning Commission to endorse the development of a comprehensive, nationwide program, and the National Malaria Control Program (NCMP) was launched in April of 1953. The timing of the program is plausibly exogenous, since it was driven by the advent of DDT.

Prior to the eradication program, malaria was considered the greatest health problem facing India. Survey evidence estimates that immediately after partition in 1947, India suffered from 75 million cases of malaria (doubled during epidemic years) and 800,000 deaths directly attributable to malaria annually (Sinton, 1935, 1936; Rao, 1959). The population of India in 1947 was 344 million, implying an annual incidence rate of $22 \%$.

Of the four human malaria parasites (Plasmodium falciparum, P. vivax, P. malariae, and $P$. ovale), two are endemic in India: $P$. vivax and $P$. falciparum. ${ }^{8} P$. falciparum is associated with the most severe forms of malaria and accounts for most malaria fatalities. It is the primary cause of malarial infections in Africa, where 90\% of malaria deaths currently occur. Data on the relative prevalence of these parasites in India during the pre-eradication era are unfortunately unavailable; data from the immediate post-eradication period suggest that approximately $30 \%$ of cases were due to P. falciparum (NMEP, 1996).

\footnotetext{
${ }^{7}$ Early experiments prior to 1910 focused on breeding control. These attempts were generally considered failures. From 1910 to 1944, various actors undertook measures such as drainage and the filling up of breeding places. The use of larvicidal chemicals such as oil, Paris green, and later pyrethrum also achieved limited success (NMEP 1986, p. 2).

${ }^{8}$ P. malariae also exists, but is confined to tribal areas of the country (NMEP, 1986).
} 
The National Malaria Control Program's main operational activity was to conduct two annual rounds of DDT spraying of human dwellings and cattle sheds. By 1956, 112 million people were estimated to be protected (NMEP, 1986). In 1958, the program was reformulated as the National Malaria Eradication Program with the goal of completely eradicating malaria from the nation, and by 1960-61, the entire country was brought under the program.

Figure 1 illustrates the rapid geographic expansion of coverage as districts were phased into the program. Once a district was incorporated into the program, it remained in the program in all subsequent years. The statement of the Planning Commission indicated that priority targeting of areas should be based on endemicity and food producing capacity. The timing of the phase-in for particular districts may therefore not be exogenous.

Large urban areas were relatively free from malaria prior to the eradication era (League of Nations, 1930). In fact, urban malaria was considered to be a negligible problem, so the NMCP left malaria control efforts to local governments. ${ }^{9}$ Prevalence of malaria in urban areas increased only later (although only to much lower levels than pre-eradication rural malaria), and the government launched an Urban Malaria Scheme in 1971 to address the growing problem of urban malaria. We therefore focus our analysis on rural areas.

While the campaign was unsuccessful in eradicating malaria from India, it did achieve tremendous reductions in malaria prevalence. The NMEP, which began tracking malaria prevalence from 1961 using blood smear data, estimates the 1965 national malaria caseload at 100,000 per year, compared to 75 million annual cases in the pre-eradication era (online Appendix Table 2). Although the 1965 figures are likely to underestimate true malaria prevalence, there is no doubt that there was a dramatic reduction in malaria prevalence over this period: both state-level data on child spleen rates and vital statistics data on malaria deaths show substantial declines during the eradication era (Appendix Table 3 and Appendix Figure 1). ${ }^{10}$

Malaria prevalence remained low throughout the 1960s but experienced a slight resurgence

\footnotetext{
${ }^{9}$ The following quote describes the treatment of urban malaria during this time: "As per the plan of operations formulated at the time of launching of the National Malaria Eradication Programme, all the roofed structures in the rural areas received indoor residual insecticidal spray except urban areas with a population of over 40,000. In such urban areas, the indoor residual insecticidal spray was confined only to the peripheral belt to a depth of 1 to $1.5 \mathrm{~km}$. Antilarval measures were recommended in towns and cities. The implementation of antilarval operations was made the responsibility of the local bodies. Due to financial constraints many local bodies failed to implement the control measures. Though malaria epidemics were recorded earlier in Bombay, Delhi, Lucknow, etc., these could be immediately contained. Hence, malaria in urban areas was not considered as a major problem” (NMEP 1996, p. 251).

${ }^{10}$ The spleen rate is a commonly used measure of childhood malaria infection over a long period.
} 
in the 1970s, peaking in 1976. However, even at the peak of the resurgence, the prevalence rate was only $1.1 \%$. Reported prevalence decreased again, although not to the low levels seen in the immediate post-eradication period. This may partially be a result of increased accuracy in reported caseloads over time.

\section{Empirical Strategy}

Our study focuses on the effects of early-life malaria exposure on subsequent human capital attainment and expenditure in adulthood. We use a differences-in-differences design, exploiting geographic variation in the prevalence of malaria prior to the eradication program. We compare outcomes at a point in time for individuals in birth cohorts born before and after the eradication era in areas with varying pre-eradication malaria prevalence. Ideally, we would know each individual's district of birth, but our outcomes data report only the district of current residence. An identifying assumption of our analysis is therefore that district of residence is a good proxy for district of birth. In the 1991 Census of India, only $7.5 \%$ of rural residents reported living in districts other than their districts of birth.

We focus on the effects of malaria exposure in very early life for two reasons, one conceptual and one practical. Infants, children, and pregnant women are at high risk for malaria related morbidity, and malaria likely exerts its most powerful influence on cognitive development and educational attainment during infancy and childhood. Second, the outcomes data we use exhibit age heaping, preventing us from employing a dose-response model as in Bleakley (2009). Bleakley allows the effect size to vary with years of exposure to eradication in childhood, which requires precise age reporting. We take an approach that places fewer demands on the quality of the age data, using a binary treatment variable to separate pre- and post-eradication cohorts. We thus use malaria prevalence at birth as an approximation of an individual's malaria exposure during the first few years of life, when the effect of malaria is likely the strongest.

To study the effects of early-life malaria exposure, we run regressions of the following form, for individual $i$ in birth cohort $c$ in district $d$ :

$$
\text { Outcome }_{i c d}=\beta(\text { Post })_{c} *(\text { Malaria })_{d}+\delta_{d}+\alpha_{c}+X_{i c d}^{\prime} \gamma_{p r e}+(\text { Post })_{c} * X_{i c d}^{\prime} \gamma_{p o s t}+\varepsilon_{i c d}
$$

where Post indicates whether the individual was born after the eradication era and Malaria is a 
measure of pre-eradication endemicity in individual $i$ 's district. ${ }^{11} \delta$ and $\alpha$ are district and birth cohort fixed effects. The vector $X$ includes membership in a scheduled caste, membership in a scheduled tribe, and household religion. The influence of this vector, captured in $\gamma$, is permitted to vary across the pre and post periods. Our coefficient of interest is $\beta$, representing the difference-indifference estimate of the effect of malaria eradication. We run specification (A) separately for men and women. In robustness checks, we add several other time-varying district-, state-, and regionlevel covariates to this specification, as well as district-specific linear trends.

To represent our results visually, we also plot cohort-specific relationships between preeradication malaria endemicity and our socioeconomic outcomes of interest. The cohort-specific relationships derive from regressions of the form:

$$
\text { Outcome }_{i c d}=\sum_{c} \beta_{c} *(\text { Malaria })_{d}+\alpha_{c}+X_{i c d}^{\prime} \gamma+\varepsilon_{i c d}
$$

where $\beta_{c}$ gives the cohort-specific relationship between pre-eradication endemicity and later-life outcomes. If malaria eradication affected the human capital accumulation and economic wellbeing of exposed cohorts, these effects should be visible in a break from preexisting trends in $\beta_{c}$. This method would also shed light on the partial effects of malaria exposure in late childhood (rather than at birth), if such effects exist. Due to age heaping on ages ending in the digits 0 and 5, we group individuals into 5-year birth cohorts for the graphical analysis, centered on years ending in the digits 2 and 7.

\section{Data}

\subsection{Map of Pre-Eradication Endemicity}

A central problem in assessing the impact of malaria is the identification of a suitable indicator for the prevalence of the disease. As Gallup and Sachs (2001) point out, the most severely affected countries often lack high-quality data on the disease burden of malaria. They use historical maps of the geographical distribution of malarial risk to derive an index of malaria prevalence.

In this paper, we use a 1948 government map that classifies areas of India into categories of

\footnotetext{
${ }^{11}$ We exclude individuals born during the eradication era (1953-1961). Although districts were phased into the program over several years during the eradication era, the timing of phase-in may be related to malaria severity and other relevant factors. In addition, measures of malaria prevalence such as the child spleen rate show declines in both sprayed and unsprayed areas over this period, suggesting that even those in unsprayed areas may have benefited from the program
} 
malaria endemicity. The map was obtained from the Ministry of Health and Family Welfare, Government of India. The pre-eradication malaria map classifies areas into six endemicity categories: (1) areas above 5000 feet; non malarious, (2) known healthy plain areas; spleen rate under 10\%, (3) variable endemicity associated with dry tracts; potential epidemic areas, (4) known areas liable to fulminant epidemic diluvial malaria, (5) moderate to high endemicity; fulminant epidemics unknown, and (6) hyperendemicity of jungly hill tracts and terai land. This map was based on spleen rate surveys and climate factors, although the exact mechanism by which category boundaries were constructed is not known.

Using geographic information system (GIS) software, we digitized the 1948 malaria endemicity map. Figure 2 shows the digitized map, overlaid with district boundaries as defined by the 1991 Census. The National Sample Survey (NSS), which we use for our outcome measures, groups some of the 466 Census districts together, resulting in 431 NSS composite "districts.” We follow the NSS district coding. We drop the island district of Lakshadweep, for which malaria prevalence data are unavailable, as well as fourteen further districts that lack observations in the NSS that satisfy our sample inclusion criteria (described below), leaving 416 districts in our main sample.

The digitization procedure subdivided districts into polygons of roughly equal size, so that some districts have more than one possible classification. To aggregate the polygons at the district level, we take two approaches. In the first approach, we average all polygon values (ranging from 1 to 6 , as described above) within a district to generate a continuous measure of endemicity, which we call the malaria index. However, the effects of malaria eradication may be nonlinear, so our second approach uses a categorical classification of pre-eradication endemicity. To generate this classification, we first map the original six-category endemicity measure into a new three category variable: categories 1 and 2 (as described above) are classified as non-malarious, categories 3 and 4 as potential epidemic, and 5 and 6 as malarious. ${ }^{12}$ We then categorize each district by its modal polygon malaria category. 77 districts do not have unique modes. For example, some mountainous districts in northern India have equal numbers of non-malarious, high altitude polygons and malarious, low altitude polygons. To avoid classifying bimodal districts arbitrarily, we omit them

(NMEP, 1986). Finally, the phase-in of the program was quite rapid, raising further difficulties in exploiting variation in timing of coverage.

${ }^{12}$ In areas where malaria is endemic, individuals can acquire limited immunity over time through years of continued exposure and multiple infections. The effects of malaria are therefore most pronounced in childhood and youth, when individuals have not acquired immunity. Immunity may also be reduced during pregnancy. In areas where malaria is 
from the analysis that uses this categorical classification.

The resulting measures of pre-eradication malaria endemicity are strongly correlated with the sequelae and ecological determinants of malaria. Figure 3 plots the state-level child spleen rate against our map-based state-level malaria index, constructed in the same way as the district-level index. In 1953-54, just as the NMEP was starting its operations, the child spleen rate was strongly positively associated with the malaria index. By 1959-60, as the eradication program was nearing completion, states converge to very low child spleen rates, so that states with high pre-eradication levels of malaria experienced the largest reductions in malaria over the eradication era. The district malaria index is also associated with known ecological determinants of malaria endemicity. (precipitation, humidity, elevation, and temperature) in the expected directions (Appendix Table 4).

The 416 districts in our sample are grouped into 75 regions according to the NSS definition of regions, and these regions are in turn grouped into 29 states. When we drop bimodal districts, we observe the following patterns. Of the 74 remaining regions, 51 (69\%) have districts in only one category of malaria endemicity, 22 (30\%) have districts in two malaria categories, and one region has districts belonging to all three malaria categories. Of the 28 remaining states, 13 (46\%) have districts in only one malaria category, another 13 (46\%) have districts in two malaria categories, and two (7\%) have districts belonging to all three malaria categories.

\subsection{Outcomes}

We use data on human capital attainment and economic status from the 43rd round of the Indian National Sample Survey (NSS), conducted in 1987. The NSS is an all-India representative household consumer expenditure survey run by the Government of India starting in 1950. The NSS has four "thick" rounds that have the largest samples: namely, 1983, 1987, 1993, and 1999. We use the 43rd round because it is the earliest thick round that contains district identifiers. Choosing an early round mitigates possible mortality bias, and using the district identifiers allows us to examine outcomes at a very local level. The NSS reports district of current residence but not district of birth.

The human capital analyses draw on literacy and primary school attainment data, whereas the economic status analyses use household-level expenditure data. ${ }^{13}$ Past research has used earnings or

epidemic, individuals may have little or no acquired immunity. In these areas, malaria can affect both children and adults and can result in severe adverse health consequences.

${ }^{13}$ We have also run our analyses using higher education outcomes, including middle school, secondary school, and college attainment. The results were substantively similar to those we report here for literacy and primary schooling. 
occupational wage data to estimate the productivity effects of childhood malaria exposure (e.g., Bleakley, 2009), under the implicit assumption that employers pay workers their marginal product. However, only seven percent of the NSS sample has a non-zero wage, and three-quarters of workers aged 20-60 (68\% of men, 78\% of women) report one of two occupations (out of 463 in the classification), both agricultural. Given the unsuitability of the labor force data, we use the survey's rich data on household consumption (including goods produced in the household) to measure the effects of eradication on economic status, measured by log household monthly per capita expenditure (measured in 1987 rupees). We trim the top and bottom one percent of the expenditure data to remove implausible values.

Because we are primarily interested in the productivity effects of malaria exposure in childhood, we restrict our consumption sample to adults of the ages with the highest labor force participation rates. Appendix Figure 2 shows age profiles in labor force participation for men and women separately. Men aged 20-60 are far more likely to work than men in other age groups or women of any age; men's labor force participation rates are well over 90 percent for most of this age interval, while women's never rise above 50 percent. We therefore focus our attention on men in this age group, whom we call prime-age men. For completeness, we report estimates for women in the same age group. ${ }^{14}$ We also examine treatment effects at the household level, which we describe in more detail below. Schedule 1 (consumer expenditure schedule) of the NSS gives information on household consumption, and Schedule 10 (employment schedule) gives information on education.

Table 1 provides summary statistics for our sample, which omits individuals born during the eradication era (1953 to 1961). For literacy and primary school completion, we analyze individuals between the ages of 15 and 75. In this sample, individuals born during 1912-1952 thus comprise the pre-eradication cohorts, whereas those born during 1962-1972 comprise the post-eradication cohorts. As discussed above, to analyze expenditures, we restrict the sample to adults aged 20-60. Here, the pre-eradication era spans 1927-1952 and the post-eradication era includes 1962-1967. 77,071 households, containing 111,308 men and 107,642 women, satisfy our inclusion criteria for the human capital outcomes.

\footnotetext{
${ }^{14}$ Many households have multiple workers, but we expect household consumption on average to be higher in households with workers who benefited from eradication. This approach is common in settings without good individual earnings data; in a recent example, Maccini and Yang (2009) regress a household-level asset ownership index on individual-level exposure to early-life economic shocks.
} 


\section{Results}

\subsection{Differences-in-Differences Analysis}

We next examine the effects of the eradication program using the differences-in-differences specification described in Section 3. We examine effects separately by gender, and include controls for membership in a scheduled caste, membership in a scheduled tribe, and indicators for the two largest religious categories (Hindu and Muslim). We also interact these controls with the posteradication dummy to allow their influence to vary across cohorts from the pre-eradication and posteradication eras.

Table 2 shows the results of our baseline specification for literacy and primary school completion, followed by several robustness checks. Panel A presents results for men, and Panel B presents results for women. Each panel shows the treatment effects using first our three category district classification (where bimodal districts are excluded) and then using our continuous endemicity index.

The results show no robust evidence of an effect of malaria eradication on human capital attainment. For example, the first column of Panel A1 shows the effects of the program on male literacy. The coefficients on post*potential epidemic and post*malarious capture the effect of being born post-eradication versus pre-eradication in a district that was formerly potentially epidemic or malarious, relative to the effect of being born in a non-malarious district. If malaria reduction increased educational attainment, we would expect these coefficients to be positive. We also report F-tests for equality of the post*potential epidemic and post*malarious coefficients. We see no significant differences in gains for those born in potential epidemic or malarious areas relative to those born in non-malarious areas. The baseline specification implies that those born in malarious areas experienced significantly smaller gains in literacy relative to those born in potential epidemic areas; however this effect is not robust to the inclusion of state* post controls (column 2), region*post controls (column 3), or the inclusion of region*post controls with district specific linear trends (column 4). We observe a similar pattern in Panel A2, which shows the effects using our continuous malaria index measure; again, positive treatment effects of the program would imply positive coefficients. The baseline specification implies a negative treatment effect, driven by the smaller gains in malarious areas relative to potential epidemic areas shown in Panel A1. However, this result is not robust to allowing differential trends by geographic area. Similarly, we observe no robust treatment effect on primary education for men. 
Panel B presents results for women, also revealing little evidence that eradication increased human capital. The literacy estimates are not statistically significant, and they change sign across specifications. The primary education results imply that those in potential epidemic and malarious areas experienced smaller gains than those in non-malarious areas; the point estimates also indicate that the gains in malarious areas were larger than those in potential epidemic areas. However, the coefficients become insignificant and change sign in our most demanding specification (region*post controls and district specific linear trends). We discuss these results further in relation to our instrumental variables estimates in Section 5.3.

We next examine the effects of the program on economic status, measured by per-capita household expenditure, as described above (Table 3). Note that these coefficients should be interpreted as the effect of being treated on household per capita consumption for men versus women, rather than the effect of treatment on male income and female income per se. Unlike the human capital results, these results indicate a positive effect of eradication per capita household consumption for treated men. In Panel A1, the baseline specification (column [1]) implies a positive, monotonic program effect across the three categories of malaria endemicity. The treatment effect estimate for potential epidemic areas relative to non-malarious areas changes sign in the robustness checks, but the differences-in-differences between potential epidemic and malarious areas, which account for over 95 percent of our sample, are always positive.

Panel A2 presents the results for men using the index measure of malaria endemicity. A one unit increase in the pre-eradication malaria index is associated with a $0.8 \%$ increase in per-capita household expenditure. To put this magnitude in context, we can convert the malaria index into an approximate measure of the corresponding spleen rate using the slope of the 1953-54 regression line in Figure 3. If we assume that malaria levels were reduced to zero in the post eradication period, this estimate implies that a 40 percentage point reduction in the spleen rate, as was experienced in the most malarious states, is associated with a 2 percent increase in per-capita household expenditure for treated men. Stated somewhat differently, a move from the ninety-fifth to the fifth percentile of the district-level malaria index distribution increases per-capita expenditure by 3 percent. The effect is quite robust to using very localized sources of geographic variation: the point estimate remains significant, and in fact increases, when we include state*post and region*post effects. When we include both region*post controls and district-specific linear trends, the effect is no longer significant but the point estimate is identical to the baseline specification. 
Notably, we do not observe significant effects of the program on per capita household expenditure for treated women (Panel B). The coefficients on post*malaria index are significantly higher for men in all specifications other than the one with district linear trends. Given women's lower rate of participation in the extra-household labor market, this suggests that the effects for men may be driven by improvements in labor market productivity arising from the eradication program. ${ }^{15}$

Note that even if the improvements in household economic status are driven through this channel, we might have expected to see improvements for women if they are married to treated men. However, the average age gap among married couples in our sample is five years: women in our treatment group are, on average, married to men born during rather than after the eradication era. We have examined the effects for women using a five year lag, and we still observe no significant effects on household expenditure (unreported). This is likely a result of the fact that the "treated" women are now in the 1967-1972 birth cohorts, making them age 15-20 at the time of the survey. ${ }^{16}$ Only $41 \%$ of this group is married, and those that are married are likely to be a quite selected group.

The possibility remains that at least part of the apparent gender differential may be driven by differences in household composition between men and women; for example, given the marital age gap, men are more likely to be married to treated women than women are to be married to treated men. We explore this possibility by running a household level regression of per capita household expenditure on pre-eradication prevalence interacted with the number of household men and women in treatment birth cohorts (1962-1967), controlling for the main effect of the number of men and women in treatment cohorts and household size (Table 3, Panel C). The results imply that having more treated men in the household, controlling for the number of treated women, results in significantly higher per capita household consumption. This is true when using the categorical or index measure of malaria prevalence. Having more treated women in the household, controlling for the number of treated men, has at most a small, insignificant effect. The difference between the index coefficients for men and women is significant at the $5 \%$ level.

\subsection{Cohort Analysis}

\footnotetext{
${ }^{15}$ The human capital results are similar if we restrict the sample to prime ages (20-60), and the expenditure results for men are similar in the unrestricted age sample (unreported). The differences in the index coefficients are statistically significantly different for men and women in all specifications except that with district linear trends.

${ }^{16}$ Note that in all the other specifications presented in the paper, in which our goal is to measure direct effects of treatment on women, treatment birth cohorts are 1962-1967. This specification is designed simply to test whether women benefit from eradication through the spousal income channel.
} 
In this section, we examine outcomes by birth cohort over time. Motivated by the differences-in-differences results, we focus on consumption effects for men. We run regression (B), using 5-year birth cohorts as described in the empirical strategy section. If the program had a positive treatment effect, we would expect to see increases in the plotted coefficients for posteradication cohorts relative to pre-eradication cohorts.

Figure 4 shows the coefficients on birth cohort*malaria index and the coefficients on birth cohort*potential epidemic and birth cohort* malarious. We observe relative improvements in percapita expenditure for those post-cohorts born in more malarious areas. If anything, relative outcomes appear to be trending down in malarious areas prior to the program and rise sharply for those born after eradication.

Our concerns that improvements for those affected by the program might reflect pre-existing trends are also alleviated by the robustness of the differences-in-differences estimates to geographic controls. This implies that any spurious trends across high and low prevalence areas would have to be reflected not only at the national level, but within state and within region as well. In the next section, we consider several possible sources of bias in our estimates.

\subsection{Robustness Analysis}

The cohort analysis gives a clear visual representation to our results, suggesting that our main estimates are not spurious. In this section, we discuss sensitivity of our results to accounting for measurement error and confounding trends.

One potential concern is whether the classifications of districts used here reflect true geographic variation in malaria prevalence in the pre-eradication period. The most likely source of bias is attenuation of the coefficients resulting from measurement error in our prevalence classifications. ${ }^{17}$ We therefore instrument for the map classifications using the ecological factors shown in Appendix Table $4 .^{18}$ Specifically, we use the interaction of the Post dummy with the district's average temperature, average elevation, average humidity, average precipitation, and squared terms in all four variables as our excluded instruments in the first-stage of our instrumental variables specifications. The second-stage equation is identical to equation (A).

\footnotetext{
${ }^{17}$ The instrumental variables estimates will produce consistent estimates if the measurement error is classical. This is an approximation in our case, given the categorical nature of the underlying variable; see Kane, Rouse and Staiger (1999).
} 
Table 4 reports the results of the IV estimates for educational and income outcomes for both men and women. For simplicity, we report all results using the malaria index measure of prevalence. The effects for men generally reflect the OLS estimates presented in Tables 2 and 3. We see implied negative treatment effects for men on educational outcomes, but these effects are not robust to the choice of geographic controls. The point estimates for per-capita expenditure are now slightly larger in magnitude than the OLS estimates.

For women, we now observe positive coefficients on the index measure for literacy and primary outcomes, although the significance is not robust to the inclusion of region*post controls. When we use the three category measure in an otherwise identical instrumental variables setup, we obtain a non-monotonic pattern as with the OLS results: malarious areas experienced improvements relative to potential epidemic areas, but both experienced smaller gains than non-malarious areas (unreported). In the OLS specifications, this non-monotonicity resulted in no overall effect when using the index measure. In the IV specifications, the difference between potential epidemic and malarious areas is more pronounced, which is likely what drives the positive net effect in the index measure. These results provide suggestive evidence that the eradication program led to improvements in educational outcomes for women in malarious areas relative to potential epidemic areas. We find no robust effects for household expenditure for affected women.

Two other potential concerns arise with evaluating the effects of changes in disease burden: selective mortality and migration. With a lower disease burden, the weakest members of affected cohorts may survive, leading to potential compositional biases when evaluating outcomes among survivors. Mortality bias is unlikely to be a problem in our experiment since the predominant form of malaria in India is $P$. vivax, which leads to morbidity but only rarely mortality. Consistent with this, the pre-eradication era estimates indicate an annual death rate from malaria of only $0.2 \%$ (NMEP 1986). In regards to migration, as mentioned above, we unfortunately do not observe individuals' districts of birth. However, only 7.5\% of individuals in rural areas are living outside their districts of birth. In addition, the robustness of our point estimates to the source of geographic variation suggests that the effects are unlikely to be driven by migration alone.

It is also unlikely that these effects can be explained by other programs whose targeting was correlated with pre-eradication endemicity. All of the results presented above control for

\footnotetext{
${ }^{18}$ The ecology data are drawn from the International Water Management Institute World Water and Climate Atlas (http://www.iwmi.org) and the Climatic Research Unit (http://www.cru.uea.ac.uk). New et al. (2002) provide a detailed
} 
interactions between individual level demographics and an indicator for being born in the post period. The expenditure results for men are also robust to controlling for an interaction between income at the district level, averaged over the pre-cohorts, and the post indicator (unreported). In order to generate the observed results, targeting would have also had to be correlated with malaria prevalence within localized geographic areas. We also directly examine one potential confounder: the early adoption of new agricultural technologies, defined by the use of high-yielding variety (HYV) seeds and chemical fertilizers in 1970, early in the Green Revolution. We do not find evidence that HYV adoption is correlated with malaria endemicity: the correlation between the district-level map index and proportion of land cropped with HYV in 1970 is -0.0019 (p-value = 0.97 ) and the correlation with the intensity of fertilizer use in 1970 is 0.0475 ( $p$-value $=0.44){ }^{19}$

As a final pair of robustness checks, we have conducted two falsification exercises using our baseline specification. In the first, we assume that eradication took place one decade earlier than in reality. If our estimates were driven by pre-existing differential trends across districts of varying malaria endemicity, then the estimate of this "placebo" treatment's effect on per capita household consumption for treated men would be positive, significant, and similar in magnitude to our main estimate. However, the coefficient on the interaction of the malaria index and a post placebo treatment dummy is small and insignificant (coef. $=0.003$, $\mathrm{SE}=0.004$ ). The second falsification test draws on the unimportance of malaria in urban areas during the pre-eradication era. Consistent with this unimportance, we find no evidence of a positive treatment effect in urban areas (coef. = $0.014, \mathrm{SE}=0.014)$.

\subsection{Interpretation of the Findings}

Our estimates shed light on whether malaria eradication had effects, but our use of the 1948 malaria endemicity classifications makes their magnitudes difficult to interpret. What do the estimates imply for individuals who grew up in India's most malarious areas? How do they compare with existing findings on eradication programs in other countries (Bleakley 2009, Lucas 2009)?

As discussed above, one way to gain further understanding from our estimates involves focusing on differences between India's most and least malarious districts. The ninety-fifth

\footnotetext{
description of the dataset. We use GIS to overlay the ecology data with district boundaries.

${ }^{19}$ To study agricultural technology adoption, we use the India Agriculture and Climate Data Set from the World Bank. For the 271 districts in the dataset, we relate the malaria index with the quantity of fertilizer used per hectare of gross
} 
percentile of the malaria index is 5.7, while the fifth percentile is 2. Therefore, a move from the ninety-fifth to the fifth percentile induces an effect equal to 3.7 times the coefficient on the interaction of post with the malaria index. The men's expenditure point estimates range from 0.008 to 0.035 , implying that a move between these two percentiles increases per-capita expenditure by 3 to 13 percent. These estimates are somewhat lower than Bleakley's estimates for male earnings in Latin America, which may be partially reconciled by the fact that our treated cohorts are relatively young; see Bleakley (2009) for further discussion. The baseline OLS regressions for women’s human capital yield imprecisely estimated zeros, but the instrumental variables procedure increases these point estimates to at least 0.013 , signifying that a move between the two percentiles increases female literacy and primary schooling by nearly 5 percentage points.

Another way to compare our results with other estimates is to rescale our coefficients to infer the effect of a ten percentage point decline in malaria incidence, as in Lucas (2009). Unfortunately, NMEP materials $(1986,1996)$ do not report pre-eradication incidence at the sub-national level, thus preventing us from directly estimating the relationship between malaria incidence and the malaria index. However, the post-eradication data are rich enough to allow us to estimate the relationship between incidence and the child spleen rate. If eradication did not alter the relationship between incidence and the spleen rate (which is plausible), we can supplement this with the information in Figure 3 on the correlation between the child spleen rate and the malaria index. Regression estimates using these data sources indicate that a ten percentage point increase in state-level malaria incidence is associated with a 28.8 percentage point rise in the child spleen rate. Furthermore, a percentage point increase in the spleen rate is associated with an increase of 0.067 in the malaria index (Figure 3). If we multiply our coefficients by the product of these two numbers, 1.93, the result tells the impact of a ten percentage point decrease in incidence.

The rescaled OLS and IV point estimates indicate that a ten percentage point decrease in incidence raises per-capita expenditure of between 1.5 and 6.8 percent. For women's human capital, the OLS results do not imply positive treatment effects. However, the rescaled IV estimates imply that a ten percentage point decrease in incidence increases female primary school attainment and literacy by 2.5 to 5.6 percentage points, with the most demanding specification (column [7] of Table 4 ) yielding estimates at the bottom of this range. These estimates are slightly higher than both

cropped area and the proportion of the gross cropped area sown with high-yielding varieties (HYV), both in 1970. 
Bleakley (2009) and Lucas (2009), who find that a change in incidence of the same magnitude raises literacy 0.08 to 2 percentage points.

Importantly, the primary malaria parasite in India differs from the primary parasite responsible for malaria in sub-Saharan Africa, where malaria is most prevalent today. The effects of present-day malaria control efforts on long-run outcomes may therefore differ from the effects estimated in this study. For instance, in the absence of an offsetting fertility response, eradication of the more fatal P. falciparum in sub-Saharan Africa is more likely to result in population growth. As a result, effects on cohorts exposed to eradication in childhood may differ in general equilibrium.

\section{Conclusion}

This paper examines the effects of a large scale eradication program that drastically reduced malaria in India over a short time period. Exploiting the heterogeneity in indigenous malaria rates and the exogenous implementation of the eradication program, we find that males exposed to malaria eradication in early childhood enjoyed higher per capita household consumption as adults. We do not observe robust treatment effects for education, which may reflect the tradeoff between schooling and labor emphasized by Bleakley (2009). The results generally imply larger treatment effects on consumption for men than for women. One possibility is that the observed effects for men are driven by increased productivity in the labor market, where male participation rates are much higher than female.

The estimated gains for men who benefited from the program are similar when we exploit national, state, or regional sources of geographic variation in pre-eradication prevalence, alleviating concerns that the effects are driven by other omitted factors. Furthermore, the results are robust to instrumenting for pre-eradication prevalence with the ecological determinants of malaria endemicity. Specifications that include district-specific time trends yield positive but imprecise estimates.

Our results and those in the accompanying articles provide support for the belief that improvements in health and in the disease environment can have a causal effect on economic wellbeing. This effect is large enough to conclude that investments in malaria control technologies such as insecticide treated nets, which cost less than $\$ 10$ and have been proven medically efficacious, likely have very high returns even without taking into account the large direct utility benefits of better health. However, the estimated effects are not large enough to provide support for the view that malaria control is a major driver of economic growth. 


\section{References}

Acemoglu, Daron and Simon Johnson (2007). "Disease and Development: The Effect of Life Expectancy on Economic Growth,” Journal of Political Economy, 115(6): 925-985.

Aikins MKS (1995). “Cost-effectiveness Analysis of Insecticide-impregnated Mosquito Nets (Bednets) Used as a Malaria Control Measure: A Study from the Gambia," PhD thesis, Department of Public Health and Policy, London School of Hygiene and Tropical Medicine, University of London.

Alleyne, George and Daniel Cohen (2002). "The Report of Working Group I of the Commission on Macroeconomics and Health,” WHO Commission on Macroeconomics and Health, April.

Barreca, Alan (2009). “The Long-Term Economic Impact of In Utero and Postnatal Exposure to Malaria,” Tulane University mimeo.

Bleakley, Hoyt (2009). "Malaria in the Americas: A Retrospective Analysis of Childhood Exposure.” American Economic Journal: Applied Economics, this issue.

Bloom, David and David Canning (2005). "Health and Economic Growth: Reconciling the Micro and Macro Evidence,” CCDRL working paper.

Brooker, S., H. Guyatt, J. Omumbo, R. Shretta, L. Drake and J. Ouman (2000). "Situation Analysis of Malaria in School-aged Children in Kenya - What Can Be Done?” Parisitology Today, 16(5): 183-186.

Card, David (2001). "Estimating the Return to Schooling: Progress on Some Persistent Econometric Problems," Econometrica 69: 1129-1160.

Clarke, S. E., M.C.H. Jukes, J.K. Njagi, L. Khasakhala, B. Cundill, J. Otido, C. Crudder, B. Estambale, S. Brooker. (2008). "Effect of Intermittent Preventive Treatment of Malaria on Health and Education in Schoolchildren: a Cluster-randomised, Double-blind, Placebo-controlled Trial.” Lancet, 372(9633), 127-138.

Davis, Kingsley (1956). “The Amazing Decline of Mortality in Underdeveloped Areas,” American Economic Review, 46(2): 305-318.

Desowitz, Robert (1991). The Malaria Capers: More Tales of Parasites and People, Research and Reality, New York: W.W. Norton.

Dunn, Frederick (2003). "Malaria." In Kenneth Kiple, ed., Cambridge Historical Dictionary of Disease. Cambridge: Cambridge University Press, pp. 203-207.

Gallup, John Luke and Jeffrey Sachs (2001). “The Economic Burden of Malaria,” American Journal of Tropical Medicine and Hygiene, 64: 85-96.

Hong, Sok Chul (2007). "A Longitudinal Analysis of the Burden of Malaria on Health and Economic Productivity: The American Case,” University of Chicago mimeo. 
Jukes, M.C.H., M. Pinder, E.L. Grigorenko, H.B. Smith, G. Walraven, E.M. Bariau, R.J. Sternberg, L.J. Drake, P. Milligan, Y.B. Cheung, B.M. Greenwood, and D.A.P. Bundy. (2006) "Long-term Impact of Malaria Chemoprophylaxis on Cognitive Ability and Educational Attainment: Followup of a Controlled Trial. Plos Clinical Trials, 1(4).

Kane, Thomas, Cecilia Rouse and Douglas Staiger (1999). "Estimating Returns to Schooling When Schooling is Misreported.” National Bureau of Economic Research Working Paper \#7235.

Kiple, Kenneth (1993). The Cambridge World History of Human Disease, Cambridge University Press.

League of Nations (1930). "Report of the Malaria Commission on its Study Tour in India,” Geneva, August.

Leighton, Charlotte and Rebecca Foster (1993). "Economic Impacts of Malaria in Kenya and Nigeria,” Major Applied Research Paper Number 6, Office of Health, Health Services Division, Bureau of Research and Development Agency for International Development.

Lucas, Adrienne (2007). “The Impact of Disease Eradication on Fertility and Education,” Wellesley College mimeo.

Lucas, Adrienne (2009). “Malaria Eradication and Educational Attainment: Evidence from Paraguay and Sri Lanka,” American Economic Journal: Applied Economics, this issue.

Maccini, Sharon, and Dean Yang (2009). "Under the Weather: Health, Schooling, and Economic Consequences of Early-Life Rainfall.” American Economic Review 99(3): 1006-1026.

New, M., D. Lister, M. Hulme, and I. Makin (2002). “A High-Resolution Data Set of Surface Climate over Global Land Areas.” Climate Research, 21: 1-25.

NMEP (1986). Malaria and its Control in India, Vol. 1. National Malaria Eradication Program, India.

NMEP (1996). Epidemiology and Control of Malaria in India. National Malaria Eradication Program, India.

Rao, B.A. (1959). Malaria in India, New Delhi: Central Health Education Bureau.

Sachs, Jeffrey and Pia Malaney (2002). “The Economic and Social Burden of Malaria,” Nature 415: 680-685.

Sinton, J. A. (1935). “What Malaria Costs India, Nationally, Socially and Economically.” Records of the Malaria Survey of India 5: 223--64 and 413-89.

Sinton, J.A . (1936). “What Malaria Costs India, Nationally, Socially and Economically.” Records of the Malaria Survey of India 6: 91--169.

World Health Organization (2001). Macroeconomics and Health: Investing in Health for Economic Development. 


\section{FIGURE 1}

Phases of the National Malaria Eradication Program

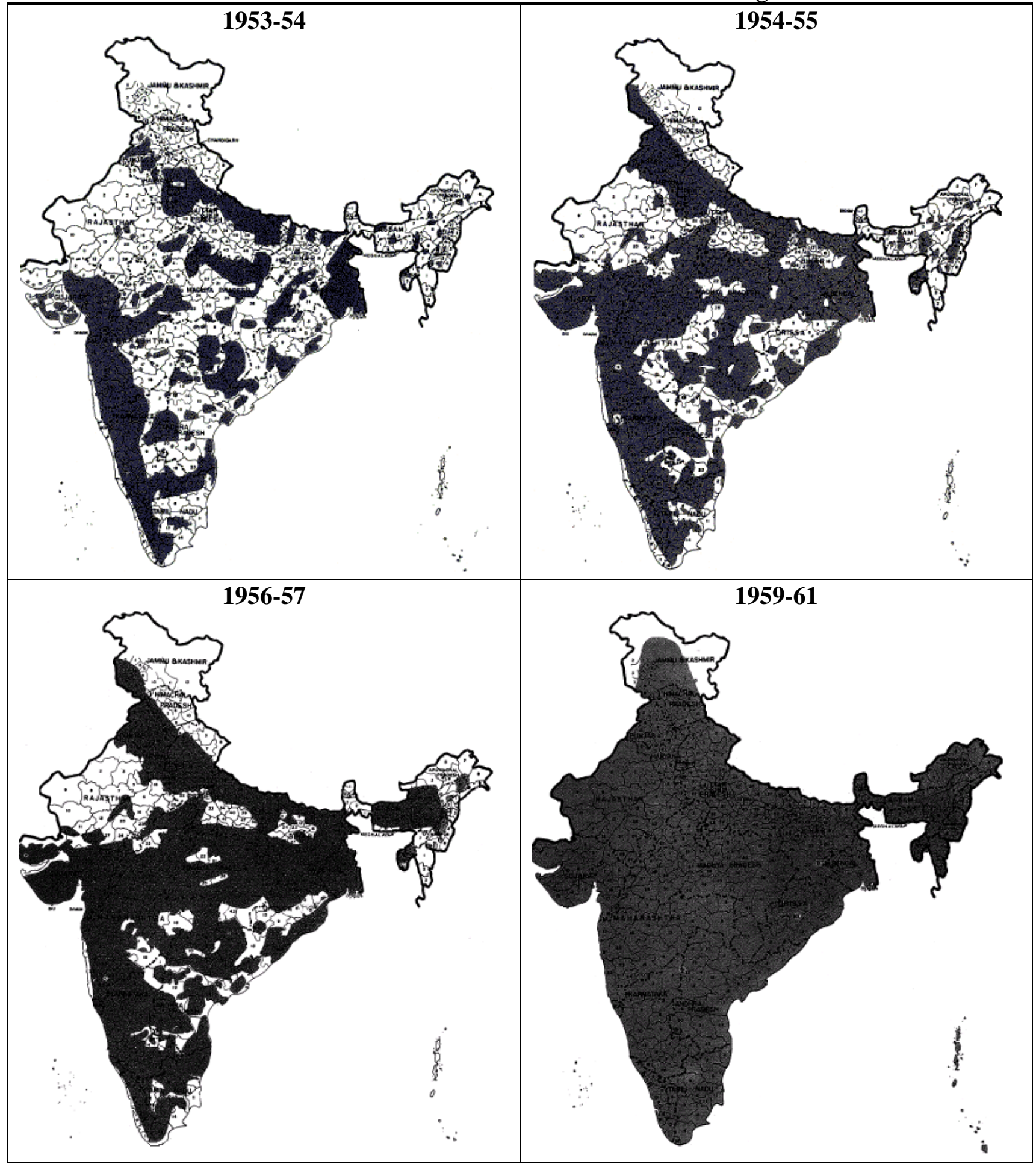

Source: NMEP (1986). Shaded areas have begun undergoing eradication efforts. 


\section{FIGURE 2}

\section{Malaria Endemicity Map}

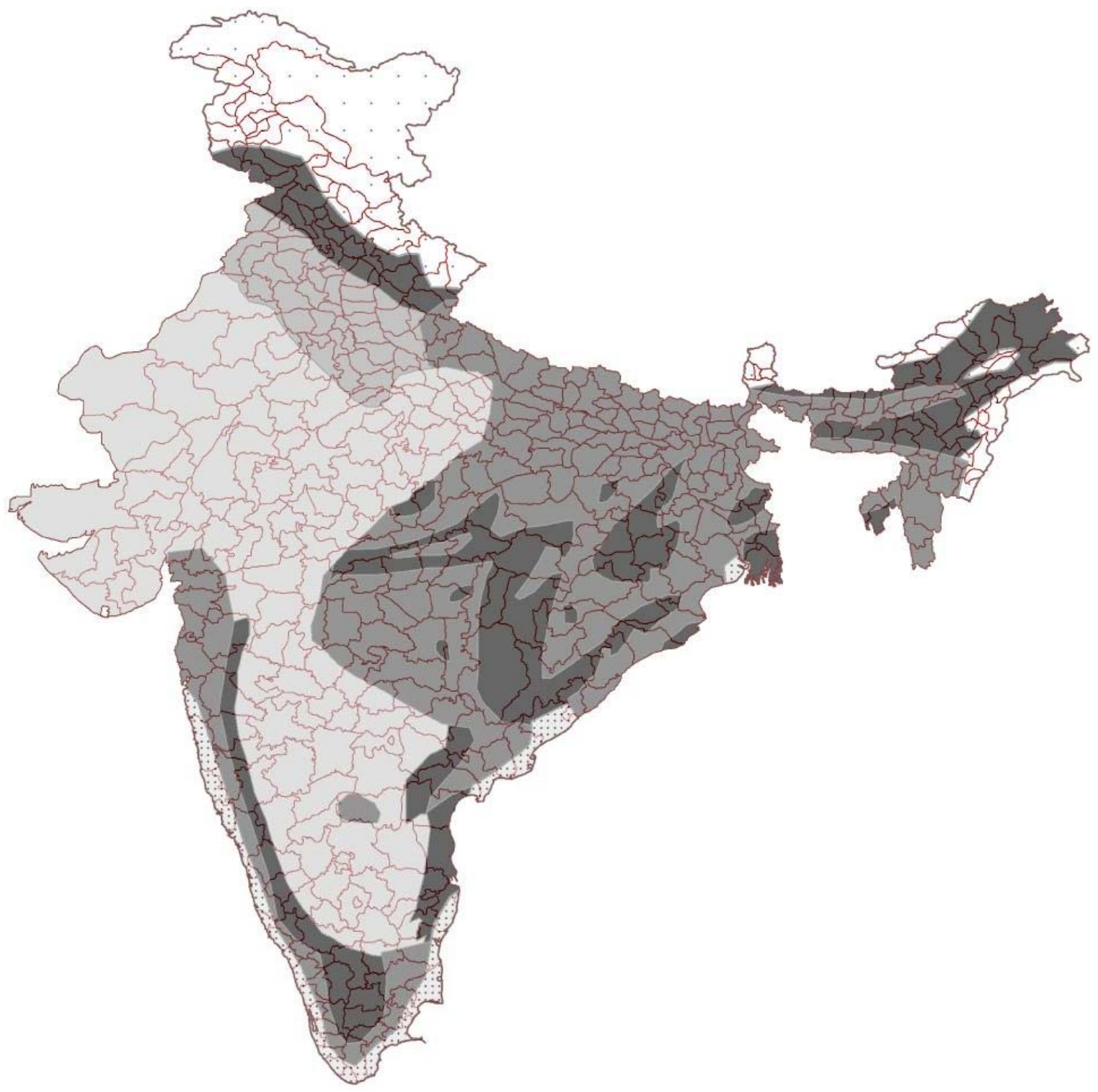

\section{Malaria Endemicity}

Areas above 5000 feet - Non-malarious

Known healthy plain areas -- Spleen rates under 10 percent

Variable endemicity associated with dry tracts -- Potential epidemic areas

Known areas liable to fulminant epidemics

Moderate to high endemic rate - Fulminant epidemics unknown

Hyperendemicity -- Jungly hill tracts and terai land 
FIGURE 3

1948 Malaria Endemicity and Child Spleen Rates in 15 States and Territories

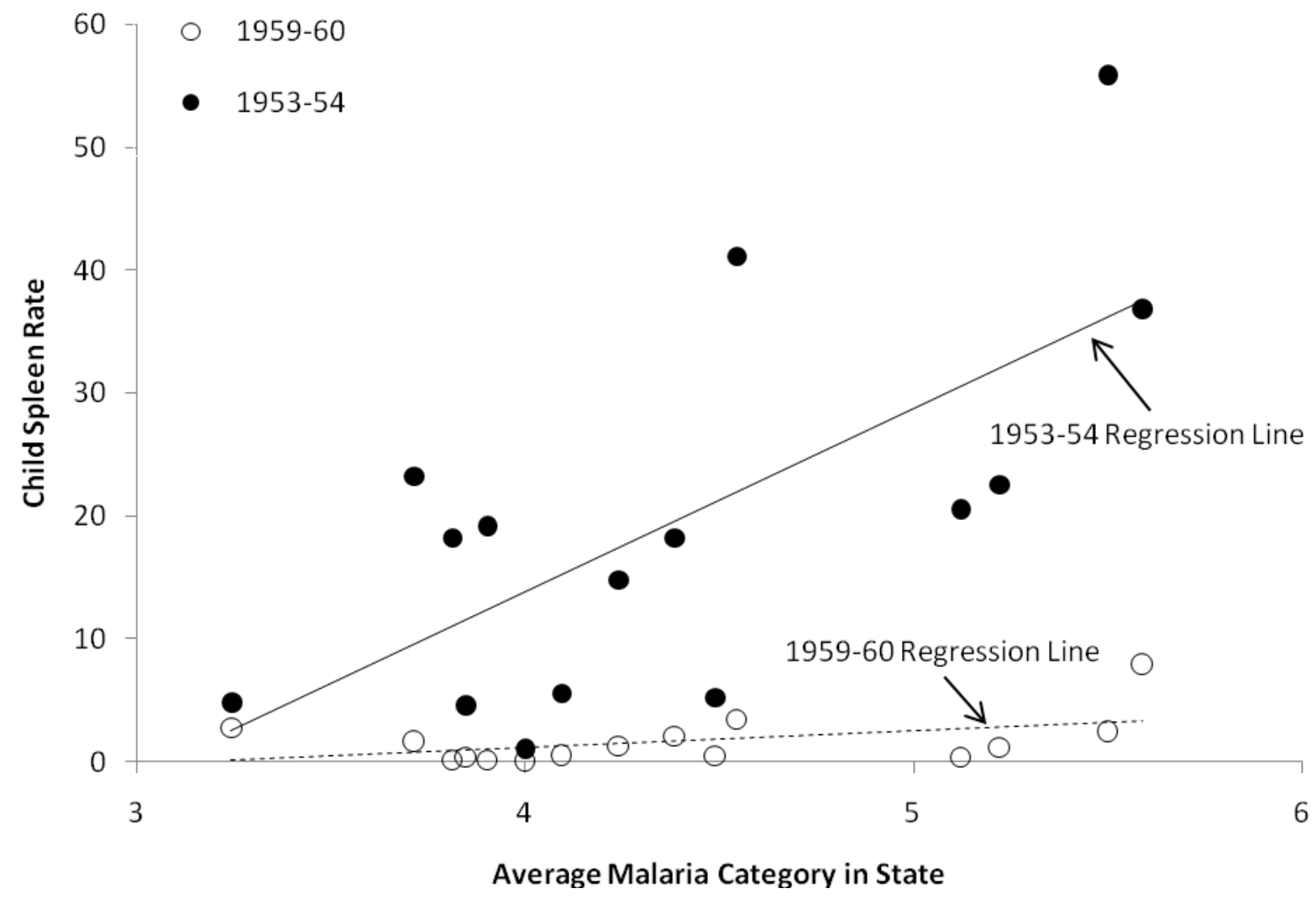

Source: NMEP (1986). Sample includes all states and territories with child spleen rate data for both 1953-54 and 1959-60. See notes to Table 3 for details on the construction of statelevel spleen rates for 1953-54. We obtain the state-level average malaria category by averaging the categories of all GIS polygons within each state. The slopes of the 1953-54 and 1959-60 regression lines, respectively, are 14.9 and 1.4 . 
FIGURE 4

Pre-Eradication Malaria Endemicity and Adult Economic Status: Cohort-Specific Relationships Households Classified by Male Birth Cohort

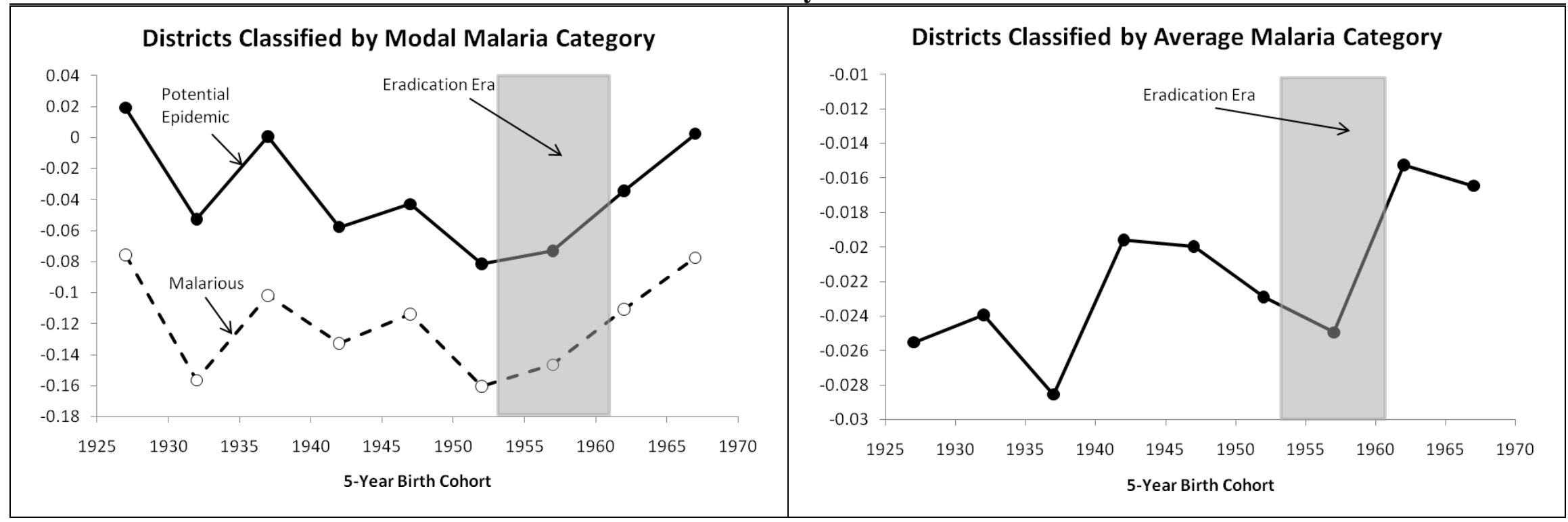

Note: Relationships were estimated in regressions of economic outcomes on cohort fixed effects and interactions of cohort fixed effects with measures of malaria endemicity: modal malaria category (relative to non-malarious) in the left panel and average malaria category in the right. The 5-year birth cohorts are centered on birth years ending in 2 and 7 (ages ending in 5 and 10). To focus on individuals of relevant ages (20+), the last birth cohort in each panel is three years long. Regressions also included dummies for membership in a scheduled caste or tribe and household religion. 
TABLE 1

Summary Statistics

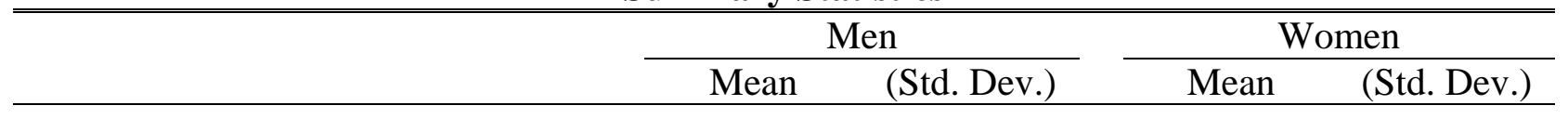

Panel A: Outcomes

Human Capital Sample (Ages 15-75)

$\begin{array}{lllll}\text { Literate } & 0.53 & (0.50) & 0.23 & (0.42) \\ \text { Primary school attainment } & 0.39 & (0.49) & 0.16 & (0.37)\end{array}$

Economic Status Sample (Ages 20-60)

Log per capita household expenditure

$\begin{array}{lll}4.97 & (0.48) & 4.97\end{array}$

Panel B: Malaria Endemicity Measures (Combined Sample)

Avg. malaria category in district (1-6) $\quad 4.38 \quad$ (0.98)

Modal malaria category in district

Non-malarious (1 and 2)

Potential epidemic (3 and 4)

0.02

$(0.14)$

$(0.98)$

Endemic malaria (5 and 6)

0.24

$(0.43)$

0.02

$(0.50)$

0.23

0.53

$(0.40)$

0.54

0.20

0.20

Panel C: Demographic Characteristics (Combined Sample)

Age

Married

36.29

$(16.61)$

36.39

Scheduled caste

0.66

$(0.47)$

0.71

$\begin{array}{ll}(0.39) & 0.18\end{array}$

Scheduled tribe

0.18

(0.30)

0.18

$(0.45)$

Hindu

0.10

$(0.36)$

0.85

(0.29)

0.85

$(0.30)$

Muslim

0.09

111,218

0.10

Number of observations

Number of states

Number of regions

Number of districts

Number of households

29
75
417
77,020

29

417

7,020

Note: Means and standard deviations are weighted using sampling weights. Sample includes rural residents and excludes those born during the eradication era (1953-1961). Panels $\mathrm{B}$ and $\mathrm{C}$ report summary statistics and sample sizes for the sample with non-missing data on at least one outcome. 
TABLE 3

Childhood Malaria Exposure and Adult Economic Status

Dependent Variable:

Log Per Capita Household Expenditure

(Ages 20-60)

(1) (2) (3)

(4)

\section{Panel A: Households Classified by Male Birth Cohort}

\section{A1. Districts Classified by Modal Malaria Category}

(Omitted Category: Post * Non-malarious)

Post * Potential Epidemic

$$
0.011
$$

$(0.015)$

Post * Malarious

0.033

0.011

$-0.054$

0.037

$(.014)^{* *}$

$(0.024)$

$(0.032)^{*}$

(0.062)

$0.034 \quad 0.018$

0.082

$(0.021) \quad(0.027)$

(0.052)

F-test: Equal Treatment Effects ( $p$-value)

Observations

$\begin{array}{cccc}0.055 & 0.080 & <0.001 & 0.187 \\ 59,906 & 59,906 & 59,906 & 59,906\end{array}$

\section{A2. Districts Classified by Average Malaria Category}

Post * Malaria Index

Observations

State*Post Fixed Effects

Region*Post Fixed Effects

District-Specific Linear Trends

$$
\begin{array}{cccc}
0.008 & 0.011 & 0.019 & 0.008 \\
(0.004)^{* *} & (0.005)^{* *} & (.006)^{* * *} & (0.011)
\end{array}
$$

$$
75,230 \quad 75,230 \quad 75,230 \quad 75,230
$$

$\mathrm{X}$

$\begin{array}{cc}\mathrm{X} & \mathrm{X} \\ \mathrm{X}\end{array}$


Dependent Variable:

Log Per Capita Household Expenditure (Ages 20-60)
(1)
(2)
(3)
(4)

Panel B: Households Classified by Female Birth Cohort

B1. Districts Classified by Modal Malaria Category

(Omitted Category: Post * Non-malarious)

Post * Potential Epidemic

$\begin{array}{cccc}0.011 & -0.006 & -0.016 & -0.014 \\ (0.015) & (0.028) & (0.039) & (0.077)\end{array}$

Post * Malarious

$\begin{array}{lll}(0.015) \quad(0.028) & (0.039)\end{array}$

$(0.077)$

$\begin{array}{llll}-0.003 & -0.014 & -0.015 & 0.027\end{array}$

$\begin{array}{llll}(0.013) & (0.024) \quad(0.031) & (0.057)\end{array}$

F-test: Equal Treatment Effects ( $p$-value)

Observations

$\begin{array}{cccc}0.163 & 0.570 & 0.967 & 0.425 \\ 59,617 & 59,617 & 59,617 & 59,617\end{array}$

B2. Districts Classified by Average Malaria Category

Post * Malaria Index

$-0.003$

$-0.003$

0.004

0.011

(0.004)

$(0.004)$

$(0.005)$

$(0.014)$

Observations

$75,212 \quad 75,212 \quad 75,212 \quad 75,212$

State*Post Fixed Effects

Region*Post Fixed Effects

District-Specific Linear Trends

$\mathrm{X}$

$\begin{array}{cc}\mathrm{X} & \mathrm{X} \\ \mathrm{X}\end{array}$ 


\section{Panel C: All Households}

\section{C1. Districts Classified by Modal Malaria Category}

Potential Epidemic*(\# Males in Treatment Cohorts) 0.040

Malarious*(\# Males in Treatment Cohorts)

Potential Epidemic*(\# Females in Treatment Cohorts) 0.031

Malarious*(\# Females in Treatment Cohorts)

F-test: Equal Treatment Effects ( $p$-values)

Males: Potential Epidemic vs. Malarious $\quad 0.004$

Females: Potential Epidemic vs. Malarious $\quad 0.158$

Potential Epidemic: Males vs. Females 0.773

Malarious: Males vs. Females $\quad 0.113$

Number of households $\quad 63,219$

\section{C2. Districts Classified by Average Malaria Category}

Malaria Index*(\# Males in Treatment Cohorts) 0.014

Malaria Index*(\# Females in Treatment Cohorts) $\quad 0.002$

F-test: Equal Treatment Effects ( $p$-values) 0.022

Number of households

79,500

Note: OLS coefficients, with standard errors in parentheses. With the exception of Panel C, sample includes rural residents from pre-eradication (1927-1952) and post-eradication (19621967) cohorts. The sample in Panels A1 and B1 omits individuals living in bimodal districts. All regressions in Panels A and B include district and year of birth fixed effects, as well as demographic covariates and their interaction with post. Demographic covariates include membership in a scheduled caste, membership in a scheduled tribe, and household religion. Regressions in Panel C include district fixed effects, demographic controls as well as household size. Standard errors in Panels A and B are clustered at the district level, and those in Panel C are heteroskedasticity robust. * significant at $10 \%$; ** significant at $5 \%$; *** significant at $1 \%$. 
TABLE 4

Instrumental Variables Estimates

\begin{tabular}{|c|c|c|c|c|c|c|}
\hline & \multicolumn{3}{|c|}{ Men/Male Birth Cohort } & \multicolumn{3}{|c|}{ Women/Female Birth Cohort } \\
\hline & (1) & $(2)$ & (3) & $(5)$ & $(6)$ & $(7)$ \\
\hline \multicolumn{7}{|l|}{ Dependent Variable: } \\
\hline $\begin{array}{l}\text { Literacy } \\
(111,000 \text { men; } 107,308 \text { women })\end{array}$ & $\begin{array}{c}-0.029 \\
(0.009) * * *\end{array}$ & $\begin{array}{c}0.018 \\
(0.010)^{*}\end{array}$ & $\begin{array}{c}0.002 \\
(0.009)\end{array}$ & $\begin{array}{c}0.013 \\
(0.009)\end{array}$ & $\begin{array}{c}0.029 \\
(0.011)^{* * *}\end{array}$ & $\begin{array}{c}0.014 \\
(0.012)\end{array}$ \\
\hline $\begin{array}{l}\text { Primary schooling } \\
(111,000 \text { men; } 107,308 \text { women })\end{array}$ & $\begin{array}{c}-0.022 \\
(0.009)^{* *}\end{array}$ & $\begin{array}{c}0.020 \\
(0.011)^{*}\end{array}$ & $\begin{array}{c}0.006 \\
(0.010)\end{array}$ & $\begin{array}{c}0.016 \\
(0.009)^{*}\end{array}$ & $\begin{array}{c}0.029 \\
(0.011)^{* * *}\end{array}$ & $\begin{array}{c}0.018 \\
(0.011)\end{array}$ \\
\hline $\begin{array}{l}\text { Log per capita H.H. expenditures } \\
(75,131 \text { men; } 75,102 \text { women })\end{array}$ & $\begin{array}{c}0.0094 \\
(0.006)^{*}\end{array}$ & $\begin{array}{c}0.026 \\
(0.010)^{* * *}\end{array}$ & $\begin{array}{c}0.035 \\
(0.015)^{* *}\end{array}$ & $\begin{array}{c}0.000 \\
(0.006)\end{array}$ & $\begin{array}{c}0.002 \\
(0.006)\end{array}$ & $\begin{array}{c}0.009 \\
(0.009)\end{array}$ \\
\hline $\begin{array}{l}\text { State*Post Fixed Effects } \\
\text { Region*Post Fixed Effects }\end{array}$ & & $\mathrm{X}$ & $X$ & & $\mathrm{X}$ & $X$ \\
\hline
\end{tabular}

Note: Each cell shows the coefficient on the malaria index from a separate regression. The excluded instruments include average temperature, average elevation, average humidity, average precipitation, and squared terms in all four variables. The sample sizes differ from Tables 2 and 3 because two districts did not have ecology data. The OLS results for the subsample used for this table are identical to those reported in earlier tables for the full sample. See column (3) of Appendix Table 4 for the district-level first stage regression. Parentheses contain standard errors clustered at the district level. The human capital sample includes rural residents from pre-eradication (1912-1952) and post-eradication (1962-1972) cohorts, whereas the consumption sample includes only the 1927-1952 and 1962-1967 cohorts. All regressions include district and year of birth fixed effects, as well as demographic covariates and their interaction with post. Demographic covariates include membership in a scheduled caste, membership in a scheduled tribe, and household religion. * significant at $10 \%$; ** significant at $5 \%$; *** significant at $1 \%$. 